Proc. of the X Int. Conf. - Ion Implantation and other Applications of Ions and Electrons, Kazimierz Dolny 2014

\title{
Ion Beam Induced Darkening in Tetrahedral Amorphous Carbon Thin Films
}

\author{
M. SAndulov ${ }^{a}$, M. Berova $^{a}$, T. TsvetKova ${ }^{a, *}$ And J. ZuK ${ }^{b}$ \\ ${ }^{a}$ Institute of Solid State Physics, Bulgarian Academy of Sciences, \\ 72 Tzarigradsko Chaussee Blvd., 1784 Sofia, Bulgaria \\ ${ }^{b}$ Institute of Physics, Maria Curie-Skłodowska University, pl. M. Curie-Skłodowskiej 1, 20-031 Lublin, Poland

\begin{abstract}
The samples of thin film $(d \approx 40 \mathrm{~nm})$ tetrahedral amorphous carbon (ta-C), deposited by the filtered cathodic vacuum arc have been implanted with $\mathrm{N}^{+}$at a fluence of $3 \times 10^{14} \mathrm{~cm}^{-2}$ and ion energy $E=20 \mathrm{keV}$. The induced structural modification of the implanted material results in a considerable change of its optical properties, best manifested by a significant shift of the optical absorption edge to lower photon energies as obtained from optical transmission measurements. This shift is accompanied by a considerable increase of the absorption coefficient (photodarkening effect) in the measured wavelength range $(350 \div 2500 \mathrm{~nm})$. These effects could be attributed to both the additional defect introduction and the increased graphitization, as confirmed by the X-ray photoelectron spectroscopy measurements. The optical contrast thus obtained (between implanted and unimplanted film materials) could be made use of in the area of high-density optical data storage using the focused ion beams.
\end{abstract}

DOI: $10.12693 /$ APhysPolA.128.953

PACS: 81.05.U-, 68.55.Ln, 42.70.Ln

\section{Introduction}

Tetrahedral amorphous carbon (ta-C) films have attracted great interest for a long time from both scientific and industrial perspectives. The term tetrahedral is used to describe amorphous carbon films with a large percentage of $s p^{3}$ bonding (up to 87\%). The films are manufactured using a variety of techniques, including filtered cathodic vacuum arc (FCVA), pulsed laser deposition (PLD), and mass selected ion beam deposition (MSIBD) [1-4]. The high $s p^{3}$ content in the films results in unique properties that include extreme hardness $(\approx 70 \mathrm{GPa})$, chemical inertness, high electrical resistivity, and wide optical band gap [5-8]. The other important factors which make the films an attractive material for coatings include a smooth surface and low friction, thermal stability and transparency over a wide spectral range. These properties also offer advantages as compared to another wide optical bandgap material - silicon carbide $(\mathrm{SiC})$ - for uses in nanoscale optical data recording for archival information storage using the focused ion beams (FIB) techniques, where $\mathrm{SiC}$ thin films have found useful applications recently [9-16].

In the case of polycrystalline silicon carbide (pc-SiC) thin films, ion bombardment is used to amorphise the areas of the films by the computer operated FIB systems, thus creating useful optical contrast between the nonirradiated polycrystalline areas and the irradiated amorphous ones, which can be further used for nanoscale optical data recording for archival information storage [9-11].

*corresponding author; e-mail: taniatsvetkova@yahoo.co.uk
In the case of the hydrogenated amorphous silicon carbide (a-SiC:H) films, the computer operated FIB systems are used both to introduce irradiation defects and additionally, to modify the amorphous structure of the films chemically, thus reducing their optical bandgap in even a more effective manner for the useful creation of optical contrast between the implanted and non-implanted areas of the film material for applications in nanoscale optical data recording [12-16].

In both polycrystalline and amorphous $\mathrm{SiC}$ film materials, a considerable part in the creation of useful optical contrast between the irradiated and non-irradiated areas of the films is played by the transformation of substantial part of the present diamond-like $\left(s p^{3}\right)$ carbon bonds before the irradiation, into graphite-like $\left(s p^{2}\right)$ carbon bonds as a result of irradiation $[11,16]$. It is expected that a similar mechanism of carbon bonds transformation would result when applying ion bombardment with different ions, e.g. nitrogen ions $\left(\mathrm{N}^{+}\right)$, in ta-C films, so that to achieve useful optical contrast between the irradiated and non-irradiated areas of the films which could possibly be of interest for further use in archival information storage.

\section{Experimental}

Thin ta-C films $(d \approx 40 \mathrm{~nm})$ were deposited on Corning glass substrates using a commercial FCVA system (Commonwealth Scientific Corporation). Carbon plasma is produced from the arc spot on the cathode, $99.999 \%$ pure graphite in high vacuum. Cathodic arcs are prolific generators of highly ionized carbon plasmas. With the FCVA technique, the plasma stream is steered through a magnetic filter to eliminate neutral particles generated at the cathode. At the filter exit, the fully ionized plasma, 
consisting of carbon ions and electrons, streams towards the substrate. The films were deposited at room temperature with an arc current of 120 A under floating conditions.

Ion implantation of $\mathrm{N}^{+}$was carried out at room temperature (RT) using a commercial broad-beam ion implanter. The ion-beam intensity was $I \approx 2 \mu \mathrm{A} / \mathrm{cm}^{2}$, the ion energy was $E=20 \mathrm{keV}$, and the ion fluence used was $D=3 \times 10^{14} \mathrm{~cm}^{-2}$. SRIM simulation programme [17] was used to determine the projected range $R_{p}=29 \mathrm{~nm}$ and the struggling $\Delta R_{p}=10 \mathrm{~nm}$ of the implanted $\mathrm{N}^{+}$ ions into the ta-C film samples $(d=40 \mathrm{~nm})$.

The optical transmission $T$ and the absolute specular reflection $R$ were measured with a Cary $5 \mathrm{E}$ spectrophotometer at normal light incidence in the range $350 \div 2500 \mathrm{~nm}$. Optical constants of the films were determined by the (TR) methods using the Newton-Raphson iterative technique [18] and the derivative free flexible Nelder-Mead simplex technique [19].

The X-ray photoelectron spectroscopy (XPS) studies were performed on the ESALAB MkII system (England) with the $\mathrm{Al} K_{\alpha}$ radiation $(1486.6 \mathrm{eV})$ and total instrumental resolution of $\approx 1 \mathrm{eV}$. The pressure in the chamber was $1 \times 10^{-8} \mathrm{~Pa}$. The binding energy (BE) was referred to the $\mathrm{C} 1 \mathrm{~s}$ line (of the adventitious carbon) at $285.0 \mathrm{eV}$. The concentrations of the element on the surface were evaluated from integrated peak areas after the Shirley-type background subtraction using the theoretical Scofield photoionization cross-section [20]. The accuracy of the measured BE was around $0.2 \mathrm{eV}$.

\section{Results and discussion}

The optical characterization of the unimplanted and $\mathrm{N}^{+}$implanted samples of ta-C films on glass substrates was performed by optical transmission measurements in the range $350 \div 2500 \mathrm{~nm}$ (Fig. 1) and the optical absorption coefficient $\alpha$ was also calculated in the same range for both types of ta-C samples (Fig. 2).

The optical transmission $(T)$ spectra show that $\mathrm{N}^{+}$implantation results in a substantial decrease of transmission in the visible range of the spectrum (Fig. 1). The related increase of the absorption coefficient $(\alpha)$ in the same range is shown to reach over $50 \%$ change in magnitude (Fig. 2), which may be sufficient to fulfill the requirements for optical contrasts needed for applications in optical data storage.

The registered optical properties modification of the ta-C films by the $\mathrm{N}^{+}$ion implantation is the result of the implantation induced structural changes and radiation defects, thus modifying the optical bandgap and the electronic properties of the films. The structural changes, resulting from the $\mathrm{N}^{+}$ion implantation induced modification, were studied by XPS spectroscopy measurements.

The XPS spectroscopy results for $\mathrm{N}^{+}$implanted ta$\mathrm{C}$ samples on glass substrates are shown in Figs. 3-5. They present the fitted $\mathrm{C} 1 s$ spectra of as deposited ta$\mathrm{C}$ (Fig. 4) and $\mathrm{N}^{+}$implanted ta-C films (Fig. 5). The



Fig. 1. Optical transmission spectra of unimplanted and $\mathrm{N}^{+}$implanted ta-C samples.



Fig. 2. Optical absorption coefficient spectra of unimplanted and $\mathrm{N}^{+}$implanted ta-C samples.

C $1 s$ spectra of both types of ta-C films are deconvoluted using four components (peaks). The peaks at $284.6 \mathrm{eV}$ and $285.4 \mathrm{eV}$ are assigned to the $\mathrm{C}-\mathrm{C}$ bond in $s p^{2}$ and $s p^{3}$ configuration. These observations are consistent with those reported elsewhere $[21,22]$. The $s p^{2}$ to $s p^{3}$ ratio of ta-C films can be determined from the relative intensities of the curve fitted XPS C $1 s$ spectra. The other peaks are attributed to $\mathrm{C}-\mathrm{O}, \mathrm{C}=\mathrm{O}$ and $\mathrm{O}-\mathrm{C}=\mathrm{O}$ bonds [23]. The $s p^{3} / s p^{2}$ ratio of the unimplanted ta-C films is calculated to be 1.24. The implantation of ta- $\mathrm{C}$ by $\mathrm{N}^{+}$ions caused change in the shape of the $\mathrm{C} 1 s$ peak. The resulting shape points to increased graphitisation, which is also supported by the data presented in the following Table (GL\% shows the Gaussian-Lorentzian sum of the peak used in the fit: $0 \%$ for Gaussian and 100\% for Lorentzian). 


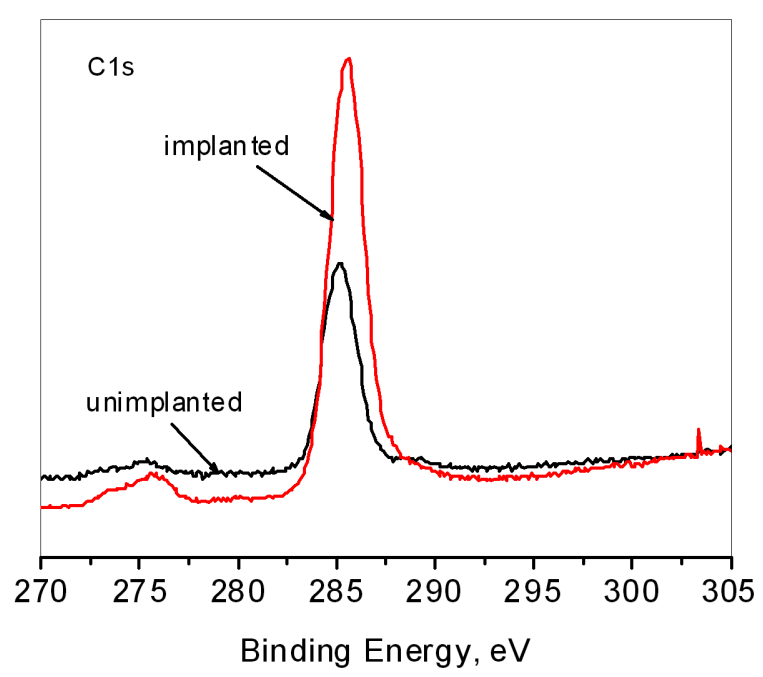

Fig. 3. XPS C $1 s$ spectra of unimplanted and $\mathrm{N}^{+}$implanted ta-C samples.

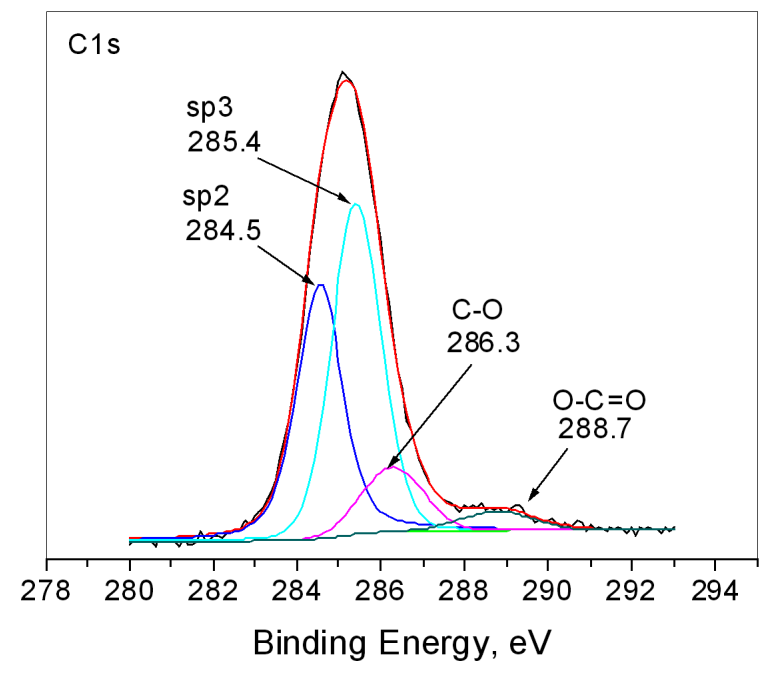

Fig. 4. Deconvoluted C $1 s$ spectrum of unimplanted ta-C sample.

TABLE

Parameters of the deconvoluted peaks of the C $1 s$ spectra for unimplanted and $\mathrm{N}^{+}$implanted ta-C samples

\begin{tabular}{c|c|c|c|c}
\hline \hline Peak & Position $[\mathrm{eV}]$ & Area & FWHM $[\mathrm{eV}]$ & \%GL [\%] \\
\hline \multicolumn{5}{c}{ C $1 s$ unimplanted } \\
\hline 0 & 284.54 & 3040.2 & 1.30 & 39 \\
1 & 285.42 & 3776.3 & 1.40 & 10 \\
2 & 286.28 & 875.4 & 1.75 & 0 \\
3 & 288.79 & 300.0 & 2.00 & 0 \\
\hline \multicolumn{5}{c}{ C $1 s$ implanted } \\
\hline 0 & 284.90 & 12868.0 & 1.80 & 3 \\
1 & 287.10 & 618.1 & 1.90 & 0 \\
2 & 288.30 & 423.5 & 2.00 & 0 \\
3 & 286.00 & 1662.7 & 1.90 & 0
\end{tabular}

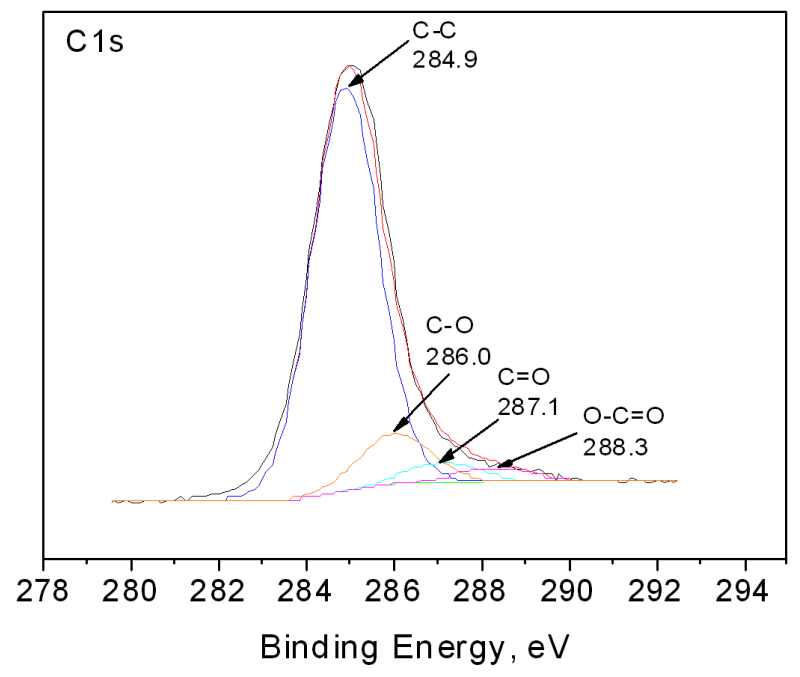

Fig. 5. Deconvoluted C $1 s$ spectrum of $\mathrm{N}^{+}$implanted ta-C sample.

\section{Conclusions}

The obtained results in the present work have shown that choosing the relatively low $\mathrm{N}^{+}$ion fluence $D=$ $3 \times 10^{14} \mathrm{~cm}^{-2}$ and energy $E=20 \mathrm{keV}$ leads to considerable modification of the structural and optical properties of the implanted ta-C films, indicating increased graphitisation and assumed electronic properties modification. The related increase of the absorption coefficient $(\alpha)$ in the visible wavelength range is shown to reach over $50 \%$ change in magnitude, which may be sufficient to fulfill the requirements for optical contrast needed for applications in optical data recording and archival information storage.

\section{Acknowledgments}

The authors would like to thank Dr. I. Avramova for the XPS measurements and analysis, as well as the group of Prof. S. Kitova for the samples preparation and their optical characterisation. The support of the Ion Beam Centre at the Maria Curie-Skłodowska University is also gratefully acknowledged.

\section{References}

[1] D.R. McKenzie, D. Muller, B.A. Pailthorpe, Phys. Rev. Lett. 67, 773 (1991).

[2] P.J. Fallon, V.S. Veerasamy, C.A. Davis, J. Robertson, G.A.J. Amaratunga, W.I. Milne, J. Koskinen, Phys. Rev. B 48, 4777 (1993).

[3] T.A. Friedmann, K.F. McCarty, J.C. Barbour, M.P. Siegal, D.C. Dibble, Appl. Phys. Lett. 68, 1643 (1996).

[4] Y. Lifshitz, S.R. Kasi, J.W. Rabalais, Phys. Rev. Lett. 62, 1290 (1989). 
[5] S.R.P. Silva, S. Xu, B.K. Tay, H.S. Tan, H.J. Scheibe, M. Chowalla, W.I. Milne, Thin Solid Films 290-291, 317 (1996).

[6] V.S. Veerasamy, J. Yuan, G. Amaratunga, W.I. Milne, K.W.R. Gilkes, M. Weiler, L.M. Brown, Phys. Rev. B 48, 17954 (1993).

[7] J. Robertson, Prog. Solid State Chem. 21, 199 (1991).

[8] S. Xu, D. Flynn, B.K. Tay, S. Prawer, K.W. Nugent, S.R.P. Silva, Y. Lifshitz, W.I. Milne, Philos. Mag. B 76, 351 (1997).

[9] B. Ruttensperger, G. Krötz, G. Müller, G. Derst, S. Kalbitzer, J. Non-Cryst. Solids 137-138, 635 (1991).

[10] G. Müller, Nucl. Instrum. Methods Phys. Res. B 80-81, 957 (1993).

[11] S. Kalbitzer, Nucl. Instrum. Methods Phys. Res. B 218, 343 (2004).

[12] T. Tsvetkova, in: Beam Processing of Advanced Materials, Eds. J. Singh, S. Copley, J. Mazumder, ASM International, Metals Park 1996, p. 207.

[13] T. Tsvetkova, S. Takahashi, A. Zayats, P. Dawson, R. Turner, L. Bischoff, O. Angelov, D. DimovaMalinovska, Vacuum 79, 94 (2005).

[14] T. Tsvetkova, S. Takahashi, A. Zayats, P. Dawson, R. Turner, L. Bischoff, O. Angelov, D. DimovaMalinovska, Vacuum 79, 100 (2005).
[15] S. Takahashi, P. Dawson, A.V. Zayats, L. Bischoff, O. Angelov, D. Dimova-Malinovska, T. Tsvetkova, P.D. Townsend, J. Phys. D Appl. Phys. 40, 7492 (2007).

[16] T. Tsvetkova, P. Sellin, R. Carius, D. DimovaMalinovska, O. Angelov, J. Optoelectron. Adv. Mater. 9, 375 (2007).

[17] J.F. Ziegler, J.P. Biersack, U. Littmark, The Stopping and Range of Ions in Matter, Vol. 1, Pergamon, New York 1985.

[18] F. Abeles, M. Theye, Surf. Sci. 5, 325 (1966).

[19] W. Press, S. Teukolsky, W. Veterling, Numeric Recipes in C, Cambridge University Press, 1992 p. 408.

[20] Handbook of X-ray and Ultraviolet Photoelectron Spectroscopy, Ed. D. Briggs, Heyden and Son, London 1977.

[21] Y. Taki, O. Takai, Thin Solid Films 316, 45 (1998).

[22] T.Y. Leung, W.F. Man, P.K. Lim, W.C. Chan, F. Gaspari, S. Zukotynski, J. Non-Cryst. Solids 254, 156 (1999).

[23] J.F. Moulder, W.F. Stickle, P.E. Sobol, Handbook of X-ray Photoelectron Spectroscopy, Perkin-Elmer, Prairie, MN 1992, p. 225. 